\title{
RESENHA
}

\section{LA FORMACIÓN DEL PROFESORADO EN PERSPECTIVA HISTÓRICA: UNA VISIÓN INTERNACIONAL}

DOI: http://dx.doi.org/10.1590/2236-3459/63490

\section{TEACHER TRAINING IN HISTORICAL PERSPECTIVE: AN INTERNATIONAL VIEW}

\author{
Mariano González-Delgado
}

Universidad de La Laguna, España.

\section{$\cos 8$}

GONZÁLEZ PÉREZ, Teresa (ed.). Reformas educativas y formación de profesores. Madrid: Biblioteca Nueva, 2015.

a relevancia de la formación del profesorado para una mejora de la calidad educativa ha sido puesta de relieve reiteradamente a lo largo de las diferentes reformas educativas en los últimos años. Desde el inicio de la construcción de los sistemas nacionales de educación, se ha entendido que el profesorado es uno de los principales agentes en la aplicación de las políticas educativas. Por este motivo, entre otros, los planes de estudio que intentan mejorar la profesionalidad docente han estado sujetos a profundos debates y modificaciones. Precisamente a esta cuestión se dedica el libro que la profesora de la Universidad de La Laguna Teresa González Pérez, ha editado dentro de la colección Memoria y crítica de la educación de la editorial Biblioteca Nueva.

El objeto de este trabajo, que ha sido abordado por diferentes especialistas en la formación docente desde una perspectiva histórica, tiene como fin estudiar los distintos modelos de formación del magisterio a lo largo de los siglos 19 y 20 . Un aspecto de gran 
interés, ya que se pueden extraer ejemplos históricos sobre la puesta en marcha, las dificultades y las particularidades que este tipo de propuestas curriculares han sufrido a lo largo de su historia en España y en otros países. De hecho, esta última cuestión es una de las más interesantes del libro. No solo podemos encontrar en él análisis sobre la peculiaridad del contexto español. Estudios concretos sobre Marruecos, Chile, México y EEUU también tienen cabida en sus páginas y ofrecen estudios de gran relevancia histórica para tener presentes en el debate actual sobre la cuestión que el libro aborda.

Desde un punto de vista formal, la obra se divide en diez capítulos. A pesar de que no existe una división interna en este sentido, se podría decir que los mismos se agrupan en tres partes o bloques diferenciados. Una primera parte dedicada al análisis de la evolución de los modelos de formación del magisterio en España; una segunda centrada en la enseñanza y desarrollo curricular de disciplinas concretas dentro de las escuelas de magisterio; y una tercera que aborda los programas de formación docente en diversos países extranjeros.

El primer capítulo, escrito por el profesor Antonio Molero Pintado, presenta un interesante recorrido histórico por la institucionalización y desarrollo de los intentos reguladores de la formación del profesorado en España desde sus inicios, siglo 19, hasta la Ley General de Educación - LGE - de 1970. Resulta de gran interés observar los primeros intentos de formación de maestros a través del Instituto Militar Pestalozziano de Madrid creado en 1805, primer antecedente o "embrión de Escuela Normal" (p. 25) en España. El capítulo avanza cronológicamente a través de los diferentes ejemplos de creación de instituciones para la formación docente.

Se hace especial énfasis en la importancia que el liberalismo español va a tener para la institucionalización de tales modelos de enseñanza. Hablamos de la creación de la Escuela Normal Central de Madrid en 1839 y de uno de sus principales ideólogos, Pablo Montesino. A pesar de que las escuelas normales florecen sin que el propio modelo de maestro esté definido, el autor nos indica la importancia que esta época tuvo para la conformación de dicho rol. Posteriormente, el análisis se centra en estudiar las reformas llevadas a cabo en la II República y su plan profesional. Se destaca la unificación del título de maestro y la ruptura de la separación entre maestros elementales y superiores, el desarrollo de las prácticas en las aulas y el aumento sistemático de la innovación pedagógica y de las metodologías didácticas. Por último, se explica la involución que supuso el primer franquismo para estos profesionales y las transformaciones modernizadoras que se produjeron en el tardofranquismo con el Cedodep y los ICEs. Este trabajo termina con la sugerente revisión de los últimos programas de formación docente y presenta detallados argumentos para sustentar un debate sobre este objeto.

A partir de aquí, la obra se introduce de lleno en analizar los modelos de formación del magisterio dentro de las políticas educativas del tardofranquismo y la Transición hacia la democracia. El trabajo de los profesores Miguel Beas Miranda, J. Antonio Lorenzo Vicente y Soledad Montes Montero se dedica, justamente, a esta cuestión. En concreto, tiene por objetivo investigar cómo se gestó la identidad profesional del magisterio en los años finales de la dictadura franquista. No obstante, para captar dicha construcción identitaria se estudia el currículum de formación de los maestros en esos años, las principales teorías pedagógicas que dominaban en el campo de las ciencias de la educación y el contexto político, económico y cultural que delimitaba los mismos. De esta 
forma, se desarrolla un análisis detallado de los planes de estudio de magisterio en los años cincuenta y sesenta. Pero también, se destaca la importancia que los diferentes organismos de formación continua del profesorado tuvieron a la hora de construir las diferentes generaciones de docentes durante esta época.

En este mismo sentido, el capítulo tercero escrito por la profesora Teresa González da una vuelta de tuerca más a esta cuestión y analiza de forma pormenorizada los planes de estudio de magisterio dentro de la LGE y la Ley Orgánica de Ordenación General del Sistema Educativa - Logse. Este capítulo se inicia con un detallado estudio de la política de formación del profesorado en los años setenta. Se denuncia, a su vez, las desigualdades de género existentes y, sobre todo, el escaso papel que el magisterio jugó en la configuración de la política educativa. A pesar de que España fuese uno de los primeros países en formar a sus maestros en el ámbito universitario, tales procesos de enseñanza fueron abiertamente insuficientes.

Los planes de estudio de los títulos de maestro estaban centrados abiertamente en una formación cultural de carácter generalista. Bajo el marco de la Transición, ya en los años ochenta, los estudios de magisterio sufrieron modificaciones notables. No solo hablamos de la eliminación de algunas disciplinas vinculadas a la política ideológica del franquismo, también de un fenómeno modernizador notable que tiene que ver con la transformación institucional que sufrieron las Escuelas Normales al pasar a estar dentro del terreno universitario. Se produjeron, de esta forma, evoluciones en términos formativos, pero también mejoras salariales, estatutarias y de prestigio de la profesión. Un aspecto que acabo de consolidarse con la llegada del Partido Socialista Obrero Español Psoe - al gobierno en 1982. No obstante, indica la autora, a pesar de las mejoras formativas como la creación de los Centros de Profesorado - CEPs - o los nuevos planes de estudio para el magisterio, existió en las diferentes reformas un olvido y distancia por parte de los administradores del estado con la cultura escolar y las preocupaciones cotidianas docentes. Un aspecto que todavía está por resolver a pesar de las mejoras indicadas.

En el capítulo cuarto, se puede observar el inicio de la configuración del segundo bloque que comentábamos más arriba. El lector podrá comprobar como aquí se presentan interesantes estudios de casos sobre la formación docente en disciplinas concretas y el importante papel jugado por los movimientos de renovación pedagógica - MRPs - en la construcción del espacio educativo a lo largo de los años setenta y ochenta del siglo 20. El trabajo de la profesora María Jesús Vera Cazorla analiza la enseñanza de la materia de Lengua Inglesa en las escuelas de magisterio a través de un examen pormenorizado del Plan de Estudios de 1971. Un aspecto interesante a destacar, son las dificultades que existieron en España para formar maestros especialistas en tan solo tres años de estudio. Ello derivó, como ha señalado la autora, en claros déficits formativos y las dificultades prácticas para impartir el inglés en las aulas. Ello produjo que diferentes generaciones de maestros de enseñanza primaria tuviesen notables dificultades para comunicarse en dicha lengua de forma natural dentro del aula a pesar de ser especialistas en la misma.

Un salto entre lo legislado y la práctica que también pone de manifiesto el profesor Juan Ramón Coello Martín en su estudio sobre la formación docente en la enseñanza de la Música y su inclusión en las escuelas en los años setenta. El problema se podía encontrar en diferentes planos. No solo que la Música se introdujo por primera vez en el 
currículum escolar con la LGE de 1970, también las dificultades para formar un profesorado específico en esta materia debido a problemas de carácter estructural, presupuestario y culturales. Lo más preocupante, señala el autor en este capítulo quinto, es que la música como disciplina escolar no se implantó como una materia obligatoria hasta 1990. Una característica deficitaria que vuelve a aparecer en la actual Ley Orgánica para la Mejora de la Calidad de la Educación - Lomce.

Otro estudio de casos, pero esta vez sobre colectivos docentes concretos y su intento por mejorar la formación del profesorado, lo podemos encontrar en el siguiente capítulo escrito por el profesor Antón Costa Rico. En este caso, el autor investiga la importancia que los MRPs tuvieron para modernizar e introducir frescas perspectivas pedagógicas durante la Transición democrática. Como indica el autor, estos movimientos fueron muy importantes en estos años, ya que "la renovación e innovación pedagógicas alcanzaron importantes cotas y dejaron de ser un impulso minoritario para convertirse en un eje central de las políticas y los quehaceres educativos" (p. 174). Estamos ante una realidad muy importante para la formación del profesorado en estos años, como el lector podrá comprobar. El capítulo comienza con un intento por explicar y conceptualizar quiénes o qué es la renovación pedagógica. Un aspecto que abarca una serie de transformaciones de diverso alcance y múltiples agentes que introdujeron innovaciones educativas. A partir de este punto, el autor nos presenta cuáles fueron los orígenes de los MRPs, sus principales enfoques sobre la formación de los docentes y la importancia que los mismos tuvieron a la hora de construir un nuevo modelo de rol docente y su contribución al cambio del contexto educativo español en esos años.

El último bloque de este libro, ofrece al lector interesantes ejemplos de formación del profesorado más allá de las fronteras españolas. El capítulo séptimo, aborda los modelos de formación del profesorado en Marruecos, un contexto poco conocido en el campo educativo internacional. La profesora Rachida Gharrafi comienza con un recorrido histórico por las principales políticas educativas llevadas a cabo en Marruecos desde su independencia en 1956 hasta la actualidad. Entre la realidad de tales reformas, destacan las diferencias que se pueden observar en el acceso a la educación entre las zonas urbanas y rurales. Un problema que afecta, especialmente, "en lo que concierne a las niñas ya que su acceso a la educación es aún más complicado" (p. 197). Este contexto de diferenciación y desigualdad, también se refleja en un perfil docente que en el medio rural se especifica por una escasa formación pedagógica. A grandes rasgos, el magisterio de las zonas rurales se define por un conocimiento de tipo coránico. La formación del profesorado, por tanto, ha estado sujeta a un debate sobre la marroquinización y arabización de los programas formativos docentes que ha tamizado las propuestas posteriores.

Un contexto diferente nos lo ofrece el profesor Jaime Caicedo Escudero con su estudio sobre los diferentes procesos de formación docente que tuvieron lugar en Chile entre 1960 y 1990. Una época que tuvo dos realidades muy diferenciadas debido a los regímenes políticos totalmente encontrados en sus propuestas. De esta manera, el autor comienza por describir las características de la formación docente dentro del gobierno de S. Allende y termina con esta misma preocupación pero con la observación de tal cuestión dentro del marco de la dictadura de Augusto Pinochet. El primer modelo se especifica por un claro intento modernizador bajo principios de carácter humanista y democrático. El 
segundo, en contra, introdujo cambios fundamentales a partir de 1973. Se inició, así, un retroceso del modelo propuesto en décadas anteriores y el sistema educativo comenzó a guiarse por las leyes del mercado - políticas de carácter neoliberal. Un aspecto que condicionó tanto la democratización de la enseñanza universitaria, como las propias mejoras e innovaciones docentes.

Sin embargo, un modelo totalmente distinto, determinado por sus principios autogestionarios y reivindicativos lo podemos observar en el capítulo noveno. La profesora Oresta López Pérez tiene por objeto señalarnos la compleja realidad de la formación del magisterio en las escuelas normales rurales de México a lo largo del siglo $X X$. Este estudio de casos nos ofrece un modelo muy particular de formación docente y su unión con la lucha política y social. $Y$ es que, las escuelas normales rurales mexicanas fueron un lugar tanto de formación docente, como de apego institucional y de ayuda hacia las comunidades campesinas. Este contexto de pobreza, exclusión y explotación en el México rural gestó un fenómeno de vínculo socio-educativo de claro carácter reivindicativo y de búsqueda me mejoras sociales para esta clase social. En este sentido, la autora nos señala como dichas escuelas fueron un "semillero de guerrilleros" (p. 267) y un lugar de creación de movimientos sociales a la contra de los terratenientes. A pesar de que en la actualidad ese marco se ha modificado, estas escuelas normales no han perdido su identidad de compromiso socio-cultural.

El libro se cierra con el capítulo escrito por la profesora Regina Cortina, el cual presenta una síntesis sobre un estudio de mayor amplitud centrado en los modelos docentes que se han desarrollado en EEUU y algunos países europeos. Este último trabajo tiene gran interés por cuanto la autora comienza por realizar una revisión de las publicaciones más actuales sobre la formación del profesorado. A renglón seguido, se analiza las condiciones de trabajo del profesorado en EEUU, así como sus expectativas laborales y autonomía docente. Por último, se reflexiona sobre un caso muy particular e interesante: la formación docente que recibe el magisterio de la ciudad de Nueva York. Un modelo que pone énfasis en las nuevas políticas educativas de carácter neoliberal centradas en los criterios de calidad, la evaluación, los exámenes de acreditación y los diferentes niveles salariales existentes. Una realidad que comenzamos a reconocer abiertamente en nuestras fronteras.

Por todo lo señalado hasta aquí, estamos ante una obra de gran relevancia e interés para las personas que se dedican al estudio de la historia de la educación o de cualquier otro campo dentro del ámbito de las ciencias de la educación. $Y$ es que, de este libro se pueden extraer varias conclusiones y enseñanzas interesantes para la actualidad. En diferentes capítulos los autores han repetido los fracasos que han supuesto algunas de las reformas que se han estudiado. La separación que suele existir entre quienes idean las leyes, los técnicos, quienes las crean, los políticos, y quienes las llevan a la práctica, los docentes, suele ser una realidad palpable en las diferentes reformas educativas. Una cuestión que analizan los especialistas que dan vida a este libro y que nos advierten sobre la necesidad de tener presente tal particularidad de cara al desarrollo del sistema educativo y la formación del profesorado en el futuro. 


\section{Referencia}

GONZÁLEZ PÉREZ, Teresa (ed.). Reformas educativas y formación de profesores. Madrid: Biblioteca Nueva, 2015.

MARIANO GONZÁLEZ-DELGADO es profesor ayudante en el Departamento de Historia y Filosofía de la Ciencia, la Educación y el Lenguaje - área de Teoría e Historia de la Educación - Universidad de La Laguna. Sus principales líneas de investigación se centran en la historia del currículum y las disciplinas escolares, la cual abarca el estudio histórico de los manuales escolares, y la modernización del sistema educativo español a través de sus influencias internacionales durante el franquismo.

Morada: Universidad de La Laguna - Facultad de Educación - Departamento de Historia y Filosofía de la Ciencia, la Educación y el Lenguaje - Avda. La Trinidad s/n - Módulo B - La Laguna, 38204 - Santa Cruz de Tenerife - España.

E-mail: mgondel@ull.edu.es.

Recebido em 12 de abril de 2016.

Aceito 19 de junho de 2016. 